
protegido. Horticultura Brasileira 34: 470-474. DOI - http://dx.doi.org/10.1590/S0102-053620160404

\title{
Compatibilidade de porta-enxertos para pimentão em cultivo protegido
}

\author{
Nuno R Madeira1; Geovani B Amaro'; Raphael AC Melo'; Claudia SC Ribeirop'; Francisco JB \\ Reifschneider ${ }^{2}$ \\ 1Embrapa Hortaliças, 70351-970 Brasília-DF, Brasil; nuno.madeira@embrapa.br; geovani.amaro@embrapa.br; raphael.melo@ \\ embrapa.br; claudia.ribeiro@embrapa.br; ${ }^{2}$ Embrapa, Secretaria de Relações Internacionais, 70770-901 Brasília-DF, Brasil; francisco. \\ reifschneider@embrapa.br
}

\section{RESUMO}

A enxertia em pimentão vem ganhando espaço em áreas em que as doenças de solo ocorrem com grande frequência, principalmente em regiões quentes e úmidas. Avaliou-se neste trabalho a compatibilidade entre quatro híbridos comerciais de pimentão (Margarita, Rubia R, Magali R e Maximos) e quatro porta-enxertos com alto vigor, tendo por controle plantas não enxertadas. Os porta-enxertos testados foram o híbrido 'Snooker', a cultivar 'BRS Mari'(Capsicum baccatum var. pendulum), a linhagem CNPH 143 e um híbrido simples experimental (HSE), além do controle constituído por plantas não enxertadas. $\mathrm{O}$ experimento foi conduzido em cultivo protegido na Embrapa Hortaliças, em Brasília-DF, no delineamento experimental de blocos casualizados, em esquema fatorial 4 x 5 (híbridos x tratamentos porta-enxertos), com três repetições. Para mensurar a compatibilidade, propõe-se um Índice de Compatibilidade (IC), calculado a partir da razão entre a produtividade comercial da cultivar porta-enxerto e a produtividade comercial da cultivar sem enxertia $(\mathrm{ICij}=\mathrm{Pij} / \mathrm{Pi})$. Não foram observadas diferenças significativas entre os híbridos avaliados para produtividade e número de frutos por planta. Quanto ao peso médio de frutos, 'Margarita' foi estatisticamente superior e com relação à compatibilidade, 'Magali R' apresentou o maior IC entre as cultivares. Dentre os porta-enxertos, HSE apresentou IC= 1,35 e 'Snooker' IC = 1,21, ou seja, a produção utilizando esses porta-enxertos superou a produção de plantas não enxertadas em $35 \%$ e em $21 \%$, respectivamente, não diferindo estatisticamente entre si sendo, todavia, superiores aos demais porta-enxertos. Quanto à produtividade e ao número de frutos, destacaram-se o HSE e 'Snooker'. Considerando-se o elevado IC, o HSE pode vir a ser uma alternativa de porta-enxerto de interesse para a cadeia produtiva de pimentão.

Palavras-chave: Capsicum annuum, Phytophthora capsici, Ralstonia solanacearum, enxertia, pimentas.

\begin{abstract}
Rootstock compatibility for sweet pepper hybrids production under greenhouse

Grafting sweet pepper is becoming widespread in areas with soil-borne diseases, especially in hot humid regions. Compatibility among four sweet pepper hybrids (Margarita, Rubia R, Magali R and Maximos) and four vigorous rootstocks was evaluated, non-grafted plants being used as controls. Rootstocks were represented by the hybrid Snooker "dedo-de-moça" (lady finger, in Portuguese) pepper cultivar BRS Mari (Capsicum baccatum var. pendulum), the breeding line CNPH 143 and an experimental single hybrid (HSE), besides aforementioned non-grafted plants as control. Evaluation was carried out under greenhouse conditions at Embrapa Vegetables, Brasília, Federal District, Brazil, in a complete randomized block with a $4 \mathrm{x}$ 5 factorial design (sweet pepper hybrids x rootstocks). For estimating compatibility, a Compatibility Index (CI) was proposed, calculated by the marketable productivity ratio between a grafted sweet-pepper hybrid and its non-grafted respective $(\mathrm{ICij}=\mathrm{Pij} / \mathrm{Pi})$. No significant difference was observed among hybrids (scions) for yield and number of fruits per plant. Hybrid Margarita was superior in average fruit weight and Magali R had the highest CI. Amongst rootstocks, HSE presented a $\mathrm{CI}=1.35$ and Snooker a $\mathrm{CI}=1.21$. Productivity using these rootstocks was higher than presented by the non-grafted plants by $35 \%$ and $21 \%$, respectively, not differing statistically from each other, but superior to the other combinations. HSE and Snooker had the highest yields and number of fruits per plant. Considering the high CI, HSE may be an interesting rootstock alternative for the sweet pepper productive chain.
\end{abstract}

Keywords: Capsicum annuum, Phytophthora capsici, Ralstonia solanacearum, grafting, pepper.

\section{(Recebido para publicação em 16 de dezembro de 2014; aceito em 5 de fevereiro de 2016)} (Received on December 16, 2014; accepted on February 5, 2016)

$\mathrm{O}$ pimentão é uma das principais hortaliças de fruto do mercado brasileiro, apresentando sazonalidade anual de oferta e preços. Para aumentar a produtividade, qualidade e oferecê-lo em todas as épocas do ano, os produtores têm utilizado o cultivo em ambiente protegido (Oliveira et al., 2009).

O Distrito Federal é um importan- te polo de produção de pimentão em cultivo protegido, permitindo a autossuficiência dessa hortaliça na capital e a exportação para outros estados da federação (COOTAQUARA, 2013). O cultivo protegido promove o controle da disponibilidade de nutrientes e água para as plantas, de aspectos físicos do ambiente e do ataque de insetos-praga e patógenos, porém exige manejo criterioso do sistema (Guedes, 2013). O uso intensivo do solo em casas de vegetação tem intensificado a ocorrência de problemas fitossanitários, causados principalmente por patógenos de solo (Salata et al., 2012). Para superar esses problemas, a enxertia de mudas vem sendo praticada com muito sucesso na 
olericultura brasileira e em diversos países (Kubota et al., 2008).

Em São Paulo, cerca de um milhão de mudas de pimentão por ano são enxertadas na tentativa de se produzir em solos contaminados por patógenos em casas de vegetação. Além disso, tem-se verificado que algumas combinações de enxerto e porta-enxerto tem a produtividade aumentada mesmo em áreas sem a presença de patógenos de solo (Santos et al., 2009). Em outros países como Espanha, Japão e Coréia do Sul, a enxertia em pimentão é realizada em mais de $70 \%$ dos cultivos em casas de vegetação (Goto et al., 2003).

$\mathrm{O}$ custo de produção de mudas enxertadas no DF é considerado alto, correspondendo a $45 \%$ do custo total de produção de pimentão cultivado em estufa (EMATER-DF, 2012). Para o investimento ter retorno financeiro, o porta-enxerto não deve possuir apenas resistência a doenças, mas também deve ter compatibilidade, mantendo a produtividade e as características da cultivar utilizada como enxerto (Jang et al., 2012). De acordo com Miguel (2007), busca-se em um porta-enxerto as seguintes características: imunidade à enfermidade que se deseja prevenir; vigor e rusticidade; boas condições para realizar o enxerto; preservação da qualidade dos frutos, sem alteração de sabor; e afinidade com a planta a enxertar.

Segundo Goto et al. (2003), o nível de compatibilidade entre enxerto e porta-enxerto é o que determina o sucesso ou o fracasso na enxertia, mas devem ser levados em consideração o método de enxertia adequado, o tamanho da superfície de contato e os fatores ambientais ideais que minimizem o estresse que a enxertia representa para as plantas. A afinidade entre o enxerto e o porta-enxerto foi definida por Miguel (2007) como o êxito da união de uma planta enxertada em outra e seu desenvolvimento como uma planta única. Entretanto, sintomas como má formação no ponto de enxertia, enrolamento de folhas, alteração no hábito de crescimento e baixa produção, suscitam o conceito de compatibilidade. O desenvolvimento de novas cultivares e/ou híbridos porta-enxertos deve focar, além da resistência e/ou tolerância a doenças de solo, a sua compatibilidade com diferentes enxertos.

O objetivo deste trabalho foi avaliar a compatibilidade entre quatro porta-enxertos e quatro híbridos comerciais de pimentão, tendo como testemunha os híbridos não enxertados.

\section{MATERIAL E MÉTODOS}

O trabalho foi conduzido na Embrapa Hortaliças, Brasília-DF (155'ㅇ' 480.' O, altitude $997 \mathrm{~m}$ ), em cultivo protegido. O solo da área experimental foi classificado como Latossolo Vermelho distrófico, típico fase cerrado e textura argilosa (Embrapa, 2006), $\mathrm{pH}$ 5,$75 ; 529,7,0 \mathrm{mg} / \mathrm{dm}^{3}$ de $\mathrm{P}, 73 \mathrm{mg} / \mathrm{dm}^{3}$ de $\mathrm{K}, 5,5 \mathrm{cmol} / \mathrm{dm}^{3} \mathrm{de} \mathrm{Ca}, 3,30 \mathrm{cmol}_{\mathrm{c}} /$ $\mathrm{dm}^{3}$ de $\mathrm{Mg}, 0,0 \mathrm{cmol}_{\mathrm{c}} / \mathrm{dm}^{3}$ de $\mathrm{Al}$ e 26,0 $\mathrm{g} / \mathrm{dm}^{3}$ de M.O.

Os híbridos de pimentão utilizados como enxerto foram 'Margarita' (Rogers), 'Rubia R' (Sakata), 'Magali R' (Sakata) e 'Maximos' (Clause), por serem os híbridos mais plantados nas principais regiões produtoras de pimentão do país. Os porta-enxertos avaliados foram o híbrido comercial de pimentão 'Snooker' (Rogers), um híbrido simples experimental de pimentão (HSE) da Embrapa Hortaliças, a cultivar de pimenta Dedo-de-Moça 'BRS Mari' (Capsicum baccatum var. pendulum) e a linhagem de pimentão CNPH 0143, com resistência à Ralstonia solanacearum. Os híbridos comerciais não enxertados (pés francos) foram utilizados como testemunhas.

O porta-enxerto HSE é resistente à podridão-de-raiz causada por Phytophthora capsici, nematoidesdas-galhas (Meloidogyne incognita raça 1) e murcha bacteriana (Ralstonia solanacearum), sendo considerado um material promissor em testes preliminares (Madeira et al., 2011).

As cultivares enxerto foram semeadas em 19/07/2009, em bandejas de 128 células, com substrato comercial Plantmax $\mathrm{HT}^{\circledR}$, dispondo-se uma semente por célula. Os porta-enxertos foram semeados em copos plásticos de $200 \mathrm{~mL}$ uma semana antes dos híbridos comerciais utilizados como enxerto. O método de enxertia usado foi do tipo garfagem fenda simples, com auxílio de bisturi e grampo para enxertia de hortaliças (Kobori, 1999; Goto et al., 2003). Após a enxertia, as mudas foram mantidas em câmara úmida com plástico e em sistema de flutuação, ou seja, em bandejas com lâmina d'água de aproximadamente $2 \mathrm{~cm}$ (De la Torre \& Miguel, 2007), retirando-se o plástico 4 dias após a enxertia e as bandejas da água 7 dias após a enxertia. $\mathrm{O}$ índice de pegamento na enxertia foi de $100 \%$, sendo feita a seleção das plantas mais vigorosas para esse experimento.

O solo foi previamente cultivado com milheto para formação de palhada para o plantio do pimentão em sistema de plantio com preparo reduzido, sistema conservacionista que tem se mostrado efetivo na melhoria dos atributos do solo (Madeira et al., 2009), deixando-se os resíduos culturais do milheto nas entrelinhas. Efetuou-se uma passada com subsolador para instalar as linhas de plantio, distanciadas $1 \mathrm{~m}$ entre si, e adubação com superfosfato simples na dosagem de $300 \mathrm{~kg} / \mathrm{ha}$ de $\mathrm{P}_{2} \mathrm{O}_{5}$ e esterco de curral curtido $(0,5 \mathrm{~L} / \mathrm{m}$ linear). $\mathrm{O}$ transplantio foi realizado em 25/09/2009, dez dias após a enxertia, no espaçamento de $0,4 \mathrm{~m}$ entre plantas nas linhas. Efetuou-se irrigação por gotejamento, tutoramento vertical e adubações quinzenais com sulfato de amônia até 75 dias após o transplante e semanais com formulação NPK 20-00-20 a partir de então, segundo recomendações técnicas para a produção de pimentão em cultivo protegido (Henz et al., 2007; Sganzerla, 1997).

O experimento foi estabelecido no delineamento em blocos casualizados, em esquema fatorial 4 x 5 (híbridos utilizados como enxertos x porta-enxertos, tendo por controle o tratamento "plantas não enxertadas"), com três repetições. A parcela foi constituída por seis plantas, utilizando-se as quatro plantas centrais como parcela útil. Foram efetuadas sete colheitas no período de 03/11/2009 até 24/03/2010, tomando-se três tamanhos de frutos comerciais: grandes $(>200 \mathrm{~g}$ e $>15 \mathrm{~cm}$ ), médios ( 120 a 200 g e 12 a 15 $\mathrm{cm}$ ) e pequenos (70 a $119 \mathrm{~g}$ e de 8 a 11,9 $\mathrm{cm})$ (Reifschneider et al., 2013). Frutos muito pequenos $(<70 \mathrm{~g} \mathrm{ou}<8 \mathrm{~cm})$ ou com deformações que comprometiam o aspecto visual foram considerados 
refugo. Efetuou-se o somatório dos frutos grandes, médios e pequenos para se obter a produtividade comercial e o somatório de frutos comerciais com frutos refugo para se obter a produtividade total.

Com o objetivo de se estabelecer melhores parâmetros para definir um bom nível de compatibilidade, é proposto neste trabalho um índice de compatibilidade (IC), obtido da razão entre a produtividade comercial da combinação enxerto e porta-enxerto e a produtividade comercial da mesma cultivar sem enxertia.

$$
I C_{i j}=P_{i j} / P_{j}
$$

onde: $I C_{i j}=$ Índice de compatibilidade entre cultivar i e porta-enxerto $\mathrm{j} ; P_{i j}$ $=$ Produção da cultivar i sobre o porta-enxerto j; $P_{i}=$ Produção da cultivar i (não enxertada).

Os dados de produtividade total $(\mathrm{PT})$, produtividade comercial $(\mathrm{PC})$, número de frutos totais por planta (NFTP), número de frutos comerciais por planta (NFCP), peso médio de frutos (PMF) e índice de compatibilidade (IC) foram analisados utilizando-se o programa estatístico SAS (SAS, 1995), sendo submetidos a análises de variância e, quando encontradas diferenças significativas, as médias foram submetidas ao teste de Scott-Knott, ao nível de 5\% de significância (Scott \& Knott, 1974).

\section{RESULTADOS E DISCUSSÃO}

\section{A interação enxerto x porta-enxerto}

não apresentou efeitos significativos para as características avaliadas, indicando que o comportamento dos porta-enxertos foi semelhante nos diferentes enxertos utilizados.

Não foram verificadas diferenças significativas entre os híbridos comerciais (enxertos) avaliados para número de frutos comerciais e totais por planta e para a produtividade comercial e produtividade total (Tabela 1). Braz et al. (2009), avaliando diferentes combinações enxertos/porta-enxertos, também observaram níveis produtivos semelhantes para as cultivares 'Maximos', 'Margarita' e 'Rubia R'.

Com relação ao peso médio de frutos, porém, observou-se a superioridade de 'Margarita' (139,1 g), certamente um dos motivos de ser a cultivar mais plantada no Distrito Federal.

É comum em hortaliças o termo compatibilidade, porém apenas se referindo à sobrevivência das plantas enxertadas (Santos \& Goto, 2006; Martins, 2012). Entretanto, ainda que haja a sobrevivência das plantas, esta pode não produzir satisfatoriamente quando comparada a uma planta sadia da mesma cultivar não enxertada (pé franco). Isso pode ocorrer em função de diferenças anatômicas ou fisiológicas.

Com relação ao índice de compatibilidade proposto, a cv. Magali R, significativamente inferior em peso médio de frutos, destacou-se por apresentar o maior índice de compatibilidade dentre as cultivares, com $\mathrm{IC}=1,31$, ou seja, a produção das plantas enxertadas supe-

Tabela 1. Produtividade total (PT) e produtividade comercial (PC), número de frutos totais por planta (NFTP), número de frutos comerciais por planta (NFCP), peso médio de frutos (PMF) e índice de compatibilidade (IC) em função do enxerto \{total yield (PT), marketable yield (PC), total number of fruits per plant (NTFP), number of marketable fruits per plant (NFCP), average fruit weight (PMF) and compatibility index (IC) depending on graftings $\}$. Brasília, Embrapa Hortaliças, 2010.

\begin{tabular}{|c|c|c|c|c|c|c|c|c|}
\hline \multirow{2}{*}{$\begin{array}{l}\text { Enxerto } \\
\text { (cv.) }\end{array}$} & PT & & PC & & \multirow{2}{*}{ NFTP } & \multirow{2}{*}{ NFCP } & \multirow{2}{*}{ PMF (g) } & \multirow{2}{*}{ IC } \\
\hline & \multicolumn{4}{|c|}{ (t/ha) } & & & & \\
\hline Máximos & 53,53 & $\mathrm{a}$ & 53,24 & a & 13,7 a & 13,5 a & $127,7 \mathrm{~b}$ & $1,10 \mathrm{~b}$ \\
\hline Margarita & 52,17 & $\mathrm{a}$ & 51,18 & 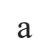 & 14,9 a & 14,2 a & 139,1 a & $1,05 \mathrm{~b}$ \\
\hline Rubia R & 51,30 & $\mathrm{a}$ & 50,13 & $\mathrm{a}$ & 16,0 a & 15,0 a & $127,9 \mathrm{~b}$ & $1,02 \mathrm{~b}$ \\
\hline Magali R & 45,16 & $\mathrm{a}$ & 44,38 & $\mathrm{a}$ & $16,7 \mathrm{a}$ & 15,9 a & $109,1 \mathrm{c}$ & $1,31 \quad a$ \\
\hline CV (\%) & 26,7 & & 27,1 & & 19,3 & 19,5 & 11,6 & 26,0 \\
\hline
\end{tabular}

Médias seguidas pela mesma letra na coluna não diferem estatisticamente entre si pelo teste de Scott \& Knott ( $\mathrm{p} \leq 5 \%$ ) (means followed by the same letter, in column, are not different by Scott \& Knott test, $5 \%$ ). rou em $31 \%$ a produção das plantas não enxertadas. Como as plantas de 'Magali R' apresentam menor vigor, podem ter sido favorecidas pela enxertia em porta-enxertos com sistema radicular mais vigoroso.

Com relação aos porta-enxertos (Tabela 2), observou-se superioridade do HSE e do híbrido comercial Snooker para produtividade total e comercial e para número de frutos comerciais e totais por planta. Não foram verificadas diferenças significativas para peso médio de frutos em função do porta-enxerto.

Quanto ao índice de compatibilidade dos porta-enxertos, destacaram-se o HSE, com $\mathrm{IC}=1,35$, e 'Snooker', com $\mathrm{IC}=1,21$. Destaca-se, ainda, o relativamente baixo IC observado em 'BRS Mari', com IC=0,95. 'BRS Mari', uma pimenta do tipo dedo-de-moça lançada pela Embrapa Hortaliças em 2008 (Reifschneider et al., 2013), foi incluída na avaliação por estar sendo utilizada como porta-enxerto para pimentão por produtores do Distrito Federal, apesar de não ter sido validada para tal finalidade. É interessante ressaltar que, mesmo ocorrendo a sobrevivência das plantas, estas podem não produzir satisfatoriamente quando comparadas a uma planta sadia da mesma cultivar não enxertada (pé franco), possivelmente em função de diferenças anatômicas ou fisiológicas.

O bom desempenho do HSE é compatível ao encontrado por Madeira et al. (2011), que observaram a superioridade do HSE e do acesso CNPH 2655 dentre 10 acessos de porta-enxertos.

Não foram observadas diferenças significativas na taxa de sobrevivência de plantas ao final do experimento, com sobrevivência média de $93 \%$ das plantas. Cabe ressaltar que não foi realizada inoculação de patógenos de solo. Possivelmente, a prática agronômica do cultivo sobre palhada de milheto, sem revolvimento do solo em área total, mas somente com o sulcamento e adubação localizada nas linhas, em um sistema de plantio com preparo reduzido, contribuiu para reduzir os problemas fitossanitários (Madeira et al., 2009). Também não se observaram alterações significativas no formato ou na qualidade dos frutos em nenhum tratamento.

Em alguns trabalhos foram avalia- 
Tabela 2. Produtividade total (PT), produtividade comercial (PC), número de frutos totais por planta (NFTP), número de frutos comerciais por planta (NFCP), peso médio de frutos (PMF) e índice de compatibilidade (IC) em função do porta-enxerto \{total yield (PT), marketable yield (PC), total number of fruits per plant (NTFP), number of marketable fruits per plant (NFCP), average fruit weight (PMF) and compatibility index (IC) by rootstocks\}. Brasília, Embrapa Hortaliças, 2010.

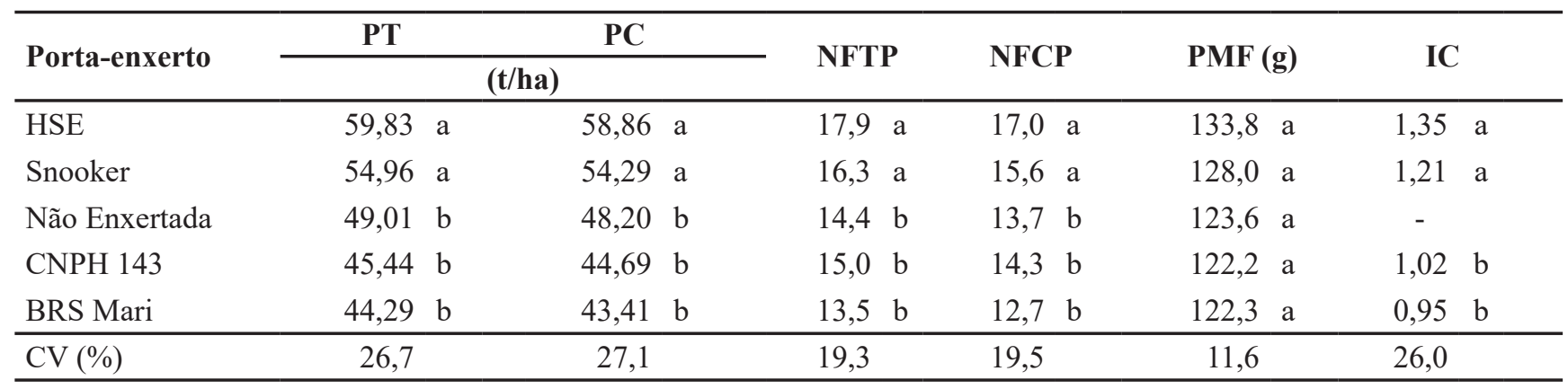

Médias seguidas pela mesma letra na coluna não diferem estatisticamente entre si pelo teste de Scott \& Knott (p $\leq 5 \%$ ) (means followed by the same letter, in column, are not different by Scott \& Knott test, 5\%).

dos a compatibilidade entre enxertos e porta-enxertos, porém sem utilizar plantas sem enxertia como testemunha. Utiliza-se, de maneira diferenciada, um índice de compatibilidade em citros baseado no diâmetro do caule abaixo e acima do ponto de enxertia (Bordignon et al., 2003; Pompeu Júnior, 2005). Rodrigues et al. (2010) definem índice de compatibilidade como a relação entre os diâmetros $10 \mathrm{~cm}$ acima e $10 \mathrm{~cm}$ abaixo do ponto de enxertia.

No caso de pimentão e, podendo-se também estender essa ideia a outras hortaliças, deve-se buscar, além de porta-enxertos com resistência ou tolerância às principais enfermidades que afetam a cultura, combinações que apresentem IC igual ou superior a 1,0 , ou seja, que produza igual ou mais que a cultivar não enxertada.

Os porta-enxertos HSE e Snooker destacaram-se pela produtividade conferida às diversas cultivares, além de apresentarem elevados índices de compatibilidade. Considerando-se a restrita disponibilidade de cultivares de porta-enxerto, os bons resultados produtivos, o elevado índice de compatibilidade $(1,35)$ e os resultados preliminares satisfatórios para resistência a doenças de solo, o HSE pode vir a ser uma opção adicional de porta-enxerto de interesse para a cadeia produtiva de pimentão.

\section{REFERÊNCIAS}

BORDIGNON, R; MEDINA FILHO,
HP; SIQUEIRA, WJ; PIO, RM. 2003. Características da laranjeira 'Valência' sobre clones e híbridos de porta-enxertos tolerantes à tristeza. Campinas, Bragantia 62: 381-395.

BRAZ, LT; OLIVEIRA, CD; SANTOS, JM; LUZ, FJF; BANZATTO, DA. 2009. Produtividade de frutos de pimentão enxertados em portaenxertos de pimentas resistentes a Meloidogyne incognita. In: CONGRESSO BRASILEIRO DE OLERICULTURA, 49. Resumos... Águas de Lindóia: ABH. p. 1278-1283.

COOTAQUARA - Cooperativa agrícola da região de Planaltina-DF. 2013. Disponível em: $<$ http://www.cootaquara.com.br/>. Acessado em 02 de julho de 2013.

DE LA TORRE, F; MIGUEL, A. 2007. Instalaciones. In: GOMEZ, AM (ed). Injerto de Hortalizas. Madrid: Ministerio de Agricultura, Pesca y Alimentación, p. 65-92.

EMATER-DF. 2012. Custos de produção. Disponível em $<$ http://www.emater.df.gov. $\mathrm{br} /$ index.php?option $=$ com content\&view $=\mathrm{a}$ rticle\&id $=75 \&$ Itemid $=87>$. Acessado em 01 de julho de 2013.

EMBRAPA. 2006. Sistema brasileiro de classificação de solos. $2^{\mathrm{a}}$ ed. Rio de Janeiro: EMBRAPA-SPI. 306p.

GOTO, R; CAÑIZARES, KAL; STRIPARI, PC. 2003. Fatores que influenciam a enxertia. In: GOTO, R; SANTOS, HS; CAÑIZARES, KAL. (org). Enxertia em Hortaliças. São Paulo: Editora UNESO. p. 25-32.

GUEDES, IMR. 2013. Greenhouse vegetable production in Brazil: current status and research needs. In: Research cooperation workshop rural development administration, Labex Korea and Embrapa. Suwon. Proceedings of the $3^{\text {rd }}$. RDA and Embrapa joint workshop: strategic research cooperation on horticulture and animal science. p.63-84.

HENZ, GP; COSTA, CSR; CARVALHO, S; BANCI, CA. 2007. Como cultivar pimentão: alta produtividade. Cultivar hortaliças $e$ frutas 7: 1-6.

JANG, Y; YANG, E; CHO, M; UM, Y; KO, K; CHUN, C. 2012. Effect of grafting on growth and incidence of Phytophthora blight and bacterial wilt of pepper (Capsicum annuum L.). Horticulture Environmental Biotechnology 53: 9-19.

KOBORI, RF. 1999. Controle da murcha de fitóftora (Phytophthora capsici) em pimentão através da enxertia. Botucatu: UNESP. 138p (Tese doutorado)

KUBOTA, C; MC CLURE, MA; KOKALLISBURELLE, N; BAUSHER, MG; ROSSKOPF, EN. 2008. Vegetable grafting: History, use, and current technology status in North America. Hortscience 43: 1664-1669.

MADEIRA, NR; AMARO, GB; SOUZA, RF; MENDONÇA, JL; REIFSCHNEIDER, FJB. 2011. Compatibilidade de porta-enxertos de Capsicum baccatum com pimentão no Distrito Federal. In: CONGRESSO BRASILEIRO DE OLERICULTURA, 51. Resumos... Viçosa: ABH. p. 2441-2447.

MADEIRA, NR; MELO, RAC; SOUZA, RB; CAIXETA, RP. 2009. Plantio direto e plantio com preparo reduzido de tomate para processamento sob diferentes níveis de adubação. In: CONGRESSO BRASILEIRO DE OLERICULTURA, 49, Águas de Lindóia, Brasília, 27: S3359-S3364. Suplemento.

MARTINS, WMO. 2012. Compatibilidade $e$ desempenho agronômico de pimentão enxertado em sistema orgânico nas condições climáticas de Rio Branco-Acre. Rio BrancoAC: UFAC. 63p (Dissertação mestrado)

MIGUEL, A. 2007. Portainjertos. In: GOMEZ, AM. Injerto de hortalizas. Madrid: Ministerio de Agricultura, Pesca y Alimentación. p. 55-64.

OLIVEIRA, CD; BRAZ, LT; SANTOS, JM; BANZATTO, DA; OLIVEIRA, PR. 2009. Resistência de pimentas a nematóides de galha e compatibilidade enxerto/porta-enxerto entre híbridos de pimentão e pimentas. Horticultura Brasileira 27: 520-526.

POMPEU JUNIOR, J. 2005. Porta-enxertos. In: MATTOS JUNIOR, D; DE NEGR, JD; PIO, RM; POMPEU JUNIOR, J. (ed). Citros. Campinas: Instituto Agronômico e Fundag, p. 61-104.

REIFSCHNEIDER, FJB; RIBEIRO, CSC; CARVALHO, SIC; AMARO, GB. 2013. BRS Mari. In: Árvore do conhecimento 
Pimenta. Disponível em http://www. agencia. cnptia.embrapa.br/gestor/pimenta/ arvore000guv5xyze $02 \mathrm{wx} 7 \mathrm{ha} 0 \mathrm{~g} 934 \mathrm{vg} 7 \mathrm{vnideo}$. html. Acessado em 02 de setembro de 2013.

RODRIGUES, MJS; LESSA, LS; RONCATTO, G; ALBUQUERQUE, MF; SOARES FILHO, WS. 2010. Avaliação de caracteres vegetativos de porta-enxerto sob laranjeira 'Aquiri' Rio Branco Acre. In: CONGRESSO BRASILEIRO DE FRUTICULTURA, 21, 2010, Natal. Frutas: saúde, inovação e responsabilidade: Anais... Natal: Sociedade Brasileira de Fruticultura. CD-ROM.

SALATA, AC; BERTOLINI, EV; MAGRO, FO;
CARDOSO, AII; WILCKEN, SRS. 2012. Enxertia e sua influência na produção de pepino e reprodução de Meloidogyne javanica e M. incognita. Horticultura Brasileira 30: 590-594.

SANTOS, HS; GOTO, G. 2006. Nível de compatibilidade de enxertia em plantas de pimentão. In: CONGRESSO BRASILEIRO DE OLERICULTURA, 49. Resumos... Águas de Lindóia: ABH. p. 1278-1283. Disponível em: http://www.abhorticultura com.br/biblioteca/arquivos/Download/ Biblioteca/46_0213.pdf. Acessado em 23 de julho de 2013.
SANTOS, HS; SILVA, RR.; SANTOS, AM. 2009. Influência da enxertia na precocidade de floração, crescimento e produção de plantas de pimentão. In: CONGRESSO BRASILEIRO DE OLERICULTURA, 49. Resumos... Águas de Lindóia: ABH. p. 1278-1283.

SAS Institute INC.SAS/STAT ${ }^{\mathrm{TM}}$ 1995. SAS user's guide for windowns environment. $6.11 \mathrm{ed}$. Cary: SAS Institute.

SCOTT, AJ; KNOTT, MA. 1974. Cluster analysis method for grouping means in the analysis of variance. Biometrics 30: 507-12.

SGANZERLA, E. 1997. Nova Agricultura: a fascinante arte de cultivar com os plásticos. Guaíba: Edit. Agropecuária. 342 p. 